\title{
Research status and prospect of waste steel fiber reinforced concrete
}

\author{
Yu Binglin ${ }^{1}$ \\ ${ }^{1}$ School of Civil Engineering and Architecture, Wuhan University of Technology, Wuhan, Hubei 430070, China
}

\begin{abstract}
Scrap steel fiber concrete (SFRC) is a new kind of concrete material, which uses the scrap steel fiber from the scrap tire as the reinforced fiber of FRP bar fiber reinforced concrete, replacing or partially replacing the traditional steel fiber and synthetic fiber. This paper summarizes the research status of waste steel fiber at home and abroad, including the mechanical properties of compressive and tensile resistance, the mixing amount and use requirements of waste steel fiber, and finally the development prospect of waste steel fiber concrete is forecasted
\end{abstract}

\section{THE INTRODUCTION}

Steel fiber reinforced concrete (SFRC) is a kind of concrete with steel fiber in random direction, which can improve the tensile strength of concrete, limit the crack development of concrete and improve the brittleness of concrete by strengthening and toughening the concrete. Steel fiber reinforced concrete has many excellent properties, such as high compressive and tensile strength, strong deformation resistance, good toughness and excellent corrosion resistance. FRP bars are combined with steel fiber reinforced concrete to form FRP bars steel fiber reinforced concrete structure to give full play to the high tensile strength of FRP bars and improve the bearing capacity of the structure; The development of crack and deformation of FRP reinforced concrete structure is limited by the effect of stress transfer between cracks of steel fiber, so as to improve the bond performance of FRP reinforced concrete and increase its service load. The energy dissipation capacity and ductility of FRP reinforced concrete structure can be improved by the toughening effect of steel fiber on concrete.The waste steel fiber reinforced concrete (SFRC) is used as the reinforcing fiber in FRP reinforced concrete by stripping the waste steel fiber from the waste tire to replace or partially replace the traditional steel fiber and synthetic fiber. At present, many scholars at home and abroad have carried out research on waste steel fiber concrete. This paper summarizes the research results of some scholars on waste steel fiber concrete Use A4 paper size $(210 \times 297 \mathrm{~mm})$ and adjust the margins to those shown in Table 1. The final printed area will be $172 \times 252 \mathrm{~mm}$.

\section{RESEARCH STATUS OF RSFRC}

\subsection{Domestic research results}

Li Yan and Lin Chaodong [1] designed and made 8 groups of industrial recycled steel fiber reinforced concrete specimens for compressive test and flexural test.The effect of volume content of recycled waste steel fiber on basic mechanical properties of concrete was studied. The results show that the industrial steel fiber has little effect on the compressive strength of concrete cube, but significantly increases the flexural strength of concrete. Compared with plain concrete, the bending toughness of recycled waste steel fiber reinforced concrete decreases slowly in the descending section of load-deflection curve, and the phenomenon of secondary peak value appears. With the increase of the volume content of recycled waste steel fiber, the load-deflection curve of concrete tends to be full and the toughness is better.

Yang Juan, Peng Gaifei, Shui Guoshuang et al. [2] used two kinds of recycled steel fibers from waste tires to prepare ultra-high performance coagulation containing coarse aggregate.The compressive strength, splitting tensile strength, fracture energy and static elastic modulus of the soil were measured. The blank group and the ultra high performance concrete mixed with ordinary steel fiber were compared. The results show that the recycled steel fiber without rubber particles is slightly disadvantageous to the compressive strength of ultrahigh performance concrete, which decreases by $3.91 \%$. The other types of steel fiber dimensions are beneficial to improve the mechanical properties of ultra-high performance concrete. However, the regenerated steel fiber with rubber particles significantly increases the fracture energy of ultra-high performance concrete, which is about 4 times that of ordinary steel fiber. In addition, the effect of regenerated steel fiber on the improvement of splitting tensile strength and static elastic modulus of UHPC is better than that of ordinary steel fiber. Recycled steel fibers, especially those with rubber particles attached, can be used as a toughening

\footnotetext{
* Corresponding author: 643373034@qq.com
} 
material to replace ordinary steel fibers in ultrahigh performance concrete construction.

Zhang Yancong and Shen Junmin [3] compared and tested the effects of the volume ratio of waste tire steel fiber and ordinary steel fiber and the strength grade of matrix concrete on the mechanical properties such as the compressive strength, splitting tensile strength and bending tensile strength of the cube.The results show that the steel fiber of waste tire can obviously enhance the strength of concrete, and can be reused as green construction material, just like waste tire rubber powder. The strength of steel fiber reinforced concrete of waste tire is lower than that of ordinary steel fiber. To achieve the same strength, the steel fiber content of waste tire should be about $40 \%$ higher than that of ordinary steel fiber. In addition, the influence of concrete strength grade on the growth rate of bending tensile strength of SFRC is weak, while the influence of compressive strength and splitting strength growth rate is negligible.

Gao Lingling [4] compared and tested the influence of waste tire steel fiber and ordinary steel fiber with different dosage on the bending toughness of cement concrete. The results show that the steel fiber of waste tire can obviously improve the toughness of concrete. With the increase of steel fiber content, the loaddeflection curve becomes fuller and the secondary load peak value increases, and the concrete is closer to the ideal elastic-plastic material. The toughness of steel fiber reinforced concrete of waste tire is lower than that of ordinary steel fiber. To achieve the same toughness, the content of steel fiber reinforced concrete should be $25 \% \sim 45 \%$ higher than that of ordinary steel fiber.

Chen Youde and Zeng Haibin [5,6] from Guangzhou University of Technology combined reclaimed aggregate with waste steel fiber and rubber particle mixture to study its mechanical properties, seismic performance of frame joints and mechanical properties of short columns Can.

Du Fangyuan [7] et al. studied the influence of hybrid recycled fibers on the mechanical properties of recycled concrete, among which, recycled fibers are steel fibers and nylon fibers separated from waste tires.

Li Yan [8] et al. studied the mechanical properties of RSF concrete, in which the length of RSF was $45 \mathrm{~mm}$ and the diameter was $1.5 \mathrm{~mm}$..Zhang Ronghua studied its workability, strength and corrosion resistance by changing the dosage of copper-plated steel fiber and waste steel fiber on the basis of reactive powder concrete, and determined the optimal dosage of RSF.

\subsection{Foreign research results}

Foreign scholars have carried out some explorations and researches on RSF reinforced concrete by replacing steel fiber with RSF obtained from waste tires or by mixing RSF with other types of fibers and applying it in general concrete.

Aiello M A[9] et al. added waste steel fibers recovered from waste tires to concrete to make recycled steel fiber reinforced coagulation (RSFRC) soil and studied its mechanical properties. Tensile test results of regenerated steel fiber dimension (RSF) show that its tensile strength is equivalent to that of industrial steel fiber dimension (ISF). The results of RSF drawing test show that the irregular shape of RSF is more favorable to the bond between steel fiber and concrete than that of ISF. By comparing two different mixing processes, the conventional mixer and the vertical planetary mixer, it was found that the permissible volume ratio of RSF with the traditional mixer was no more than $0.26 \%$, while the permissible volume ratio of RSF with the vertical planetary mixer could be increased to $0.46 \%$, and satisfactory processability and more uniform fiber distribution could be obtained.

G.Centonze[10] evaluated the post-cracking properties of recycled fiber reinforced concrete (RFRC) through tests on flexural members and slabs. The effectiveness of recycled fiber was evaluated by comparing with the experimental data of industrial fiber concrete (IFRC). All the new mixing hardening properties of concrete mixtures were tested and evaluated. The post cracking performance of RSFRC obtained by bending test is similar to that of ISFRC. RSFRC specimens have good energy absorption performance and residual strength after cracking.

Antonio Caggiano[11] summarized the results of experimental studies on "sustainable" cement-based composites with internal reinforcement of industrial and recycled steel fibers, which can be recovered from waste tires and used to replace and/or add industrial steelfibers.Specifically, six concrete mixtures, including varying amounts of industrial/recycled steel fibers, were produced and tested in compression and bending. The results confirm the prospects of the authors' previous research on the recycling of steel fiber reinforced concrete from waste wheel tires. In addition, they clearly show that, provided that the recycled fibers have sufficient properties, an equal amount of recycled fibers can be substituted for industrial fibers without significant degradation of the relevant mechanical properties.

Ozkan Sengul[12] introduced the experimental results of producing fiber-reinforced concrete using steel fiber recovered from waste tires.Waste fibers with different geometrical properties were used in different mixtures. In order to obtain reference concrete, ordinary mixtures containing no fibers and mixtures containing commercial steel fibers were also prepared. The mechanical properties such as compressive strength, splitting strength and bending strength of the composites were measured. The load-deformation behavior, including the post-peak response, was monitored through a closed-loop bending test device. The test results show that the fiber of waste tire is recovered The effect of dimension on the mechanical properties of concrete is similar to that of commercial fiber. According to the geometrical properties and fiber content of the fibers, the descending branch of the load-flexure curve is corrected by using the waste fibers, which affects the toughness of the concrete.Comparison of these curves shows that the performance of waste fibers is lower than that of commercial fibers. According to the test results and the relative cost of the mixture, the optimal fiber type and content were determined by multi-objective synchronous 
optimization technology. The experimental results show that it is feasible to produce fiber reinforced concrete from waste fiber. SFRC was prepared from three kinds of SFRC with different geometrical characteristics. The mechanical properties of SFRC were studied and compared with ordinary concrete and commercial SFRC. The results show that with the increase of fiber content, the slump of concrete decreases gradually, which is similar to that of commercial steel fiber. At the same dosage, the increase of aspect ratio of fiber will also reduce the slump of concrete. There is no obvious influence on the compressive strength, bending strength and splitting tensile strength of concrete by the waste steel fiber recovered from the waste tire.

The main purpose of the research project carried out by Jacek Domski[13] was to test scrap steel fibers and compare their properties with the most popular engineering steel fibers. This includes tensile strength estimated in accordance with EN ISO 6892-1:2009, ductility tests conducted in accordance with EN102181:1994, and tensile strength after the ductility tests. Scrap steel fibers have higher tensile strength and ductility than engineering steel fibers. The stress and strain characteristics of the two types of fibers are also significantly different. Conducted bending affects the tensile strength and elastic modulus of all test wastes and engineering steel fibers. The knowledge gained will contribute to the creation of sustainable steel fiber reinforced concrete in a more efficient manner. The test results show that WSF has higher tensile strength and ductility than ESF.After all steel fibers are bent, their tensile strength and elastic modulus will be affected. WSF can withstand bending times about three times as much as ESF.Hu H[13] et al. used recycled tire steel wire rope (RTSC) and recycled tire steel fiber (RTSF) to make steel fiber reinforced concrete (SFRC), studied its mechanical properties, and compared it with the traditional artificial steel fiber (MSF) reinforced concrete, and studied the feasibility of replacing MSF with recycled steel fiber under the same total fiber content. The test results show that the tensile strength of RTSC is higher than that of MSF, and the drawing performance of RTSC is similar to that of traditional MSF class. The critical embedding length of the RTSC in concrete is $25-40 \mathrm{~mm}$, so the recommended length range of the RTSC is $50-60 \mathrm{~mm}$.

Martinelli E[14] et al. mixed $0.5 \%$ volume fraction of steel fiber into concrete, studied the mechanical properties of hybrid steel fiber reinforced concrete (FRC) by changing the mixing ratio of industrial steel fiber (ISF) and recycled steel fiber (RSF), and compared it with ordinary concrete. The results show that the addition of steel fiber has almost no effect on the compressive strength of concrete, and there is no significant difference between FRC containing only ISF or RSF. The existence of steel fiber has a significant effect on the flexural performance of concrete and greatly enhances its toughness. Replacing ISF with the same amount of RSF weakens the post-cracking behavior of concrete, and the greater the amount of RSF, the more significant the decrease of the post-cracking toughness of the specimen. Although the content of steel fiber in concrete is low, the equivalent fracture energy of FRC is significantly increased compared with that of ordinary concrete.

Ahmadi M [15, such as use of recycled coarse aggregate instead of natural coarse aggregate, and adding steel fiber, were studied with recycled fibers and aggregate of coagulation soil mechanics performance. Research shows that: the use of recycled aggregate replacement of natural aggregate can make the compressive strength of concrete is reduced, when $100 \%$ replacement, fell by $10 \%$. The compressive strength of adding $0.5 \%$ steel fiber can be improved the compressive strength of $10 \%$, while the addition of $1 \%$ recycled steel fiber, reduces the compressive strength because too much steel fiber will create voids in the concrete test block.

Caggianoa et al. [16] studied the mechanical properties of hybrid fiber concrete by mixing industrial steel fiber (ISF) and recycled steel fiber (RSF) with different contents into concrete. It is found that the geometric characteristics of RSF depend on the sources and processing methods of waste tires.

Al-Musawi $\mathrm{H}$ et $\mathrm{Al}$. [17] studied the bending properties of fast hardening concrete by adding regenerated steel fiber, and the cement types used were calcium sulfoaluminate cement (CSA) and calcium aluminate cement (RSC).The results show that the recycled steel fiber has a significant effect on the strength and elastic modulus of the specimens. When the recycled steel fiber $(45 \mathrm{~kg} / \mathrm{m} 3)$ is added, the bending strength of the concrete made of CSA and RSC cement increases by about $36 \% \sim 70 \%$ and $24 \% \sim 41 \%$, respectively.

Grzymski F[18] et al. studied the effectiveness of recycled steel fiber in improving the ductility of concrete, and compared it with typical end-hook steel fiber concrete and ordinary concrete. The basic mechanical properties of three groups of cube blocks and beam specimens with different materials were tested. It is found that the mechanical properties of the steel fibers recovered from machining wastes vary greatly, and the use of this steel fiber cannot obtain the fiber reinforced concrete with stable properties.

\section{LOOK}

The main source of waste steel fiber is waste tires. According to statistics, 1.4 billion tons of tyres are produced worldwide every year, and a large number of tyres are discarded at the end of their useful life. The resulting waste tires pose the following threats to the environment: mosquito breeding, high flammability, easy to cause fire, non-degradable in the natural environment, and landfill treatment will pollute the soil and groundwater. In 2003, the European Union banned landfills for used tyres. In 2009, China's production of tires by the consumption of rubber has accounted for about $70 \%$ of the country's total consumption of rubber resources, resulting in 233 million waste tires, the weight of about 8.6 million tons, equivalent to about 3 million tons of rubber resources. Therefore, it is extremely 
urgent to find a feasible way to recycle and utilize waste tires.

At present, some scholars at home and abroad have paid much attention to the industrial recycling of waste tires by separating rubber particles and waste steel fibers as raw materials for civil engineering. Recycling of waste tires mainly uses mechanical and chemical processes, including tire crushing, pyrolysis and low temperature decomposition. The grinding process is usually completed in specific steps according to the required size of the product, and the steel fiber, rubber block and particles in the grinding process are separated by electromagnetic suction. In the low temperature process, the tire is frozen to a suitable temperature and then ground; Pyrolysis is usually done in a high pressure cellar, where the shredded tires are decomposed at high temperatures. However, from an economic point of view, the tire pyrolysis process is not an effective measure as it consumes a large amount of energy and the final product is of low commercial value and quality. Therefore, the main recycling method is to separate the steel fiber and rubber particles after crushing the tire. Research has shown that the industrial products obtained from waste tire recycling have great potential in the application of civil engineering. The rubber particles produced by waste tires can partially replace coarse and fine aggregate, and the rubber concrete thus produced has the characteristics of light weight, elastic shock absorption, noise reduction and sound insulation, thermal insulation, excellent impact resistance, good toughness, etc. [19-23].Waste tire production the steel fiber produced can partially or completely replace the industrial steel fiber, and the resulting waste steel fiber concrete has similar mechanical properties with the industrial steel fiber concrete [24-25].At the same time, the joint use of the two fibers can not only reduce production costs and greenhouse gas emissions, but also improve the mechanical properties of concrete, such as improving the flexural and tensile properties of vegetable concrete and restraining the cracking of concrete [26].Therefore, recycling and reuse of used tires not only solves the problem of environmental pollution and energy consumption, but also produces green new high-performance concrete with excellent performance, environmental friendlyand sustainable development.

At present, there are few researches on waste steel fiber reinforced concrete in China. In recent years, there are more and more researches on replacing traditional fiber with scrap steel fiber abroad. From the perspective of resource recycling and environmental protection Angle, it is meaningful to use waste steel fiber as sustainable concrete material. But at present, the research on the use of waste steel fiber in concrete is mainly focused on the basic mechanical properties of waste steel fiber concrete. On the other hand, the flexural problems of FRP reinforced concrete beams can be effectively alleviated by mixing reinforced fibers into the beams. However, the reinforced fibers selected by scholars at home and abroad are mainly industrial steel fibers, synthetic fibers and glass fibers, without considering the use of scrap steel fibers. Therefore, it is of certain value to use scrap steel fiber to replace or partially replace the traditional fiber dimension and explore its applicability to improve the flexural performance of FRP reinforced concrete beams. It can not only play the purpose of recycling waste resources, protecting ecological environment and sustainable development, but also solve the problems such as large mid-span deflection, wide crack and brittle failure of FRP reinforced concrete beams when they are bent, and improve the ductility and bearing capacity of FRP reinforced concrete beams. In addition, the study of the flexural behavior of waste steel fiber concrete beams with FRP bars has a certain guiding role in promoting the application of waste steel fiber reinforced concrete and FRP bars in the engineering field.

\section{Reference}

1. Li Yan, Lin Chaodong. Study on Mechanical Properties of Industrial Recyclable Steel Fiber Reinforcement Concrete [J].Sichuan Building Materials, 2018, 44 (3) : 4-5.

2. Yang Juan, Peng Gaifei, Shui Guoshuang. Mechanical properties of recycled steel fiber reinforced ultra-high performance concrete $[\mathrm{J}]$.The composite material Journal of materials: 1-8.

3. Zhang Yancong, Shen Junmin. Experimental Study on Mechanical Properties of Steel Fiber Reinforcement Concrete with Waste Tire [J].China and Foreign Highway, 2018, 38 (5) : 221-224.

4. Gao Lingling. Experimental Study on the Bending Toughness of Steel Fiber Reinforcement Concrete with Waste Tire [J].New building materials,

5. Zeng Haibin. Research on Seismic Performance of Waste Steel Fiber Rubber Recycled Concrete Frame Joins [D].Guangdong University of Technology, 2014.

6. Chen Youde. Study on Mechanical Properties of Waste Steel Fiber Rubber Recycled Concrete Short Columns [D].Guangdong University of Technology, 2013.

7. Du Yuanfang, Wang Shiliang, Yu Binshan, et al. Study on the Influence of Hybrid Recycled Fiber on the Strength of Recycled Concrete [J].Industrial Construction, 2013, (11):12-15.

8. Li Yan, Lin Chaodong. Study on Mechanical Properties of Industrial Recyclable Steel Fiber Reinforcement Concrete [J].Sichuan Building Materials, 2018, 44(3):4-5.

9. Aiello M A, Leuzzi F, Centonze G, et al. Use of steel fibres recovered from waste tyres as reinforcement in concrete:pull-out behaviour, compressive and flexural strength $[\mathrm{J}]$. Waste Manag, 2009, 29(6):.1960-70.

10. Centonze G, Leone M, Aiello M A. Steel fibers from waste tires as reinforcement inconcrete:A mechanical characterization[J]. Construction and Building Materials,2012, 36:46-57.

11. Sengul O. Mechanical behavior of concretes containing waste steel fibers recovered from scrap 
tires[J] Construction and Building Materials,2016, 122:649-658.

12. Martinelli E, Caggiano A, Xargay H. An experimental study on the post-cracking behaviour of Hybrid Industrial/Recycled Steel FibreReinforced Concrete[J]. Construction| and Building Materials, 2015, 94290-298.

13. Sengul O. Mechanical behavior of concretes containing waste steel fibers recovered| from scrap tires $[\mathrm{J}]$ Construction and Building Materials, 2016, 122:649-658.

14. Ahmadi M, Farzin S, Hassani A, et al. Mechanical properties of the concrete containing recycled fibers and aggregates[J] Construction and Building Materials, 2017, 144:392-398.

15. Caggiano A, Folino P, Lima C, et al. On the mechanical response of Hybrid Fiber Reinforced Concrete with Recycled and Industrial Steel Fibers $[\mathrm{J}]$. Construction and Building Materials,2017, 147:286-295. 36:46-57.

16. A-Musawi H, Figueiredo F P, Bermal S A, et al. Performance of rapid hardeningrecycled clean steel fibre materials[J]. Construction and Building Materials, 2019,195:483-496.

17. Grzymski F, Musial M, Trapko T. Mechanical properties of fibre reinforced concrete with recycled fibres([] Construction and Building Materials, 2019, 198:323-331.

18. WANG Baomin, LIU Wei. Research Progress of Cement Concrete Mixed with Waste Rubber Particles in Foreign Countries [J].Concrete, 2010, (4) : $54+103-56$.

19. Pan Dongping, Liu Feng, Li Lijuan, et al. Application and Research Overview of Rubber Concrete [J].Rubber Industry, 2007, (3) : 182-185.

20. LI Yue, WANG Ling. Review on Research Progress of Rubber Aggregate Concrete [J].Concrete, 2006, (04):91-93+95. (in Chinese)Experimental study on performance of cement concrete mixed with waste tire rubber powder [D]. Dalian University of Technology, 2010.

21. GuoS, DaiQ, Si R, et al. Evaluation of properties and performance of rubber-modified concrete for recycling of waste scrap tire[J]. Journal of Cleaner Production,2017,148:68 1-689.

22. Onuaguluchi O, Banthia N. Scrap tire steel fiber as a substitute for commercial steel fiber in cement mortar: Engineering properties and cost-benefit analyses[J] o Resources,Conservation and Recycling, 2018, 134:248-256.

23. Mastali M, Dalvand A, Sattarifard A R, et al. Development of eco-efficient and cost-effective reinforced self- consolidation concretes with hybrid industrial/recycled steel fibers[J]. Construction and Building Materials, 2018, 166:214-226.

24. Centonze G, Leone M, Aiello M A. Steel fibers from waste tires as reinforcement in concrete: A mechanical characterization[J]. Construction and Building Materials, 2012,36:46-57.

25. Yang Chengjiao.Experimental study on mechanical properties and durability of hybrid fiber reinforced concrete [D]. Dalian University of Technology, 2007 